\title{
Economic perspective of evaluating fertility treatment in obese and overweight infertile women
}

\author{
Munazzah Rafique, MD, MRCOG, Ahmad Al-Badr, MD, Ahmed Saleh, MD, Dania H. Al-Jaroudi, MD.
}

\begin{abstract}
الأهداف : لتقييم التكلفة المباشرة لدورة الإخصاب في المختبر / ل حقن النطفة

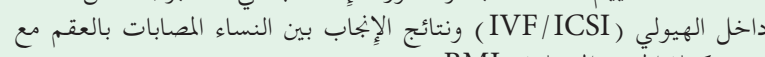
مؤشر كتلة الجُسم المختلفة (BMI (B) ).

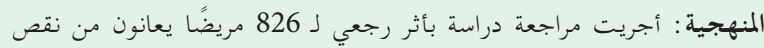

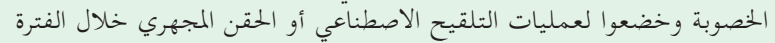

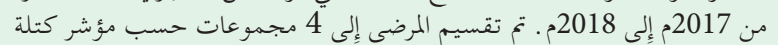

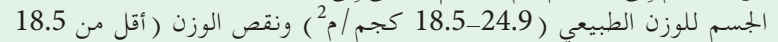

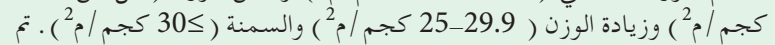

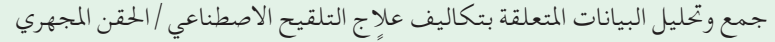

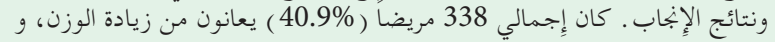

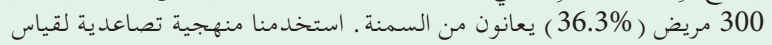

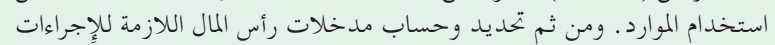

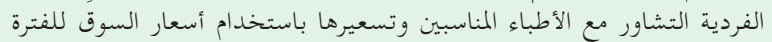
2017-2018

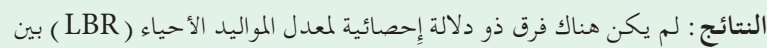

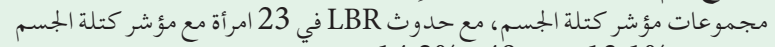

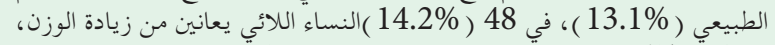

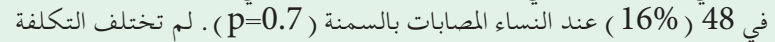

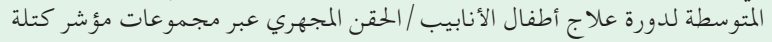

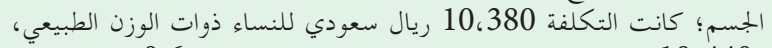

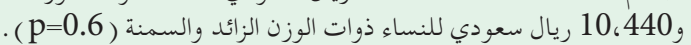

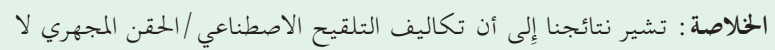

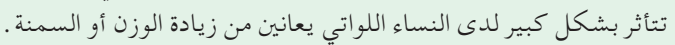

Objectives: To evaluate direct cost of in-vitro fertilization/ intracytoplasmic sperm injection (IVF/ICSI) cycle and reproductive outcomes among infertile women with different body mass index (BMI).

Methods: A retrospective study of 826 subfertility patients who had IVF or IVF-ICSI in 2017 to 2018 were reviewed. The patients were divided into 4 groups bestowing to BMI to normal weight $\left(18.5-24.9 \mathrm{~kg} / \mathrm{m}^{2}\right)$, underweight $\left(<18.5 \mathrm{~kg} / \mathrm{m}^{2}\right)$, overweight $\left(25-29.9 \mathrm{~kg} / \mathrm{m}^{2}\right)$, and obese $\left(\geq 30 \mathrm{~kg} / \mathrm{m}^{2}\right)$. Data on treatment costs of IVF/ICSI and reproductive outcomes were collected and analyzed. A total of 338 patients (40.9\%) were overweight, and 300 (36.3\%) patients were obese. A bottom-up methodology was used to measure the resource utilization. The capital inputs needed for individual procedures were defined and calculated by consulting with appropriate clinicians and priced using market prices for 2017-2018.

Results: There was no statistical significant difference for live birth rate (LBR) among the BMI groups, with the occurrence of LBR in 23 women with normal BMI $(13.1 \%)$, in $48(14.2 \%)$ women who were overweight, in $48(16 \%)$ in women who were obese $(p=0.7)$. The median cost for IVF/ICSI treatment cycle did not differ across BMI groups; the cost was 10,380 SAR for women of normal weight, 10,440 SAR for women who are overweight and obese $(p=0.6)$.

Conclusion: Our results suggest that costs of IVF/IVFICSI is not significantly affected in women who are overweight or obese.

Keywords: overweight, obesity, cost, BMI, IVF

Saudi Med J 2021; Vol. 42 (6): 666-672 doi: 10.15537/smj.2021.42.6.20200733

From the Women's Specialized Hospital (Rafique, Al-Badr); from the Research Center (Saleh), Reproductive Endocrinology \& Infertility Medicine Department (Al-Jaroudi), King Fahad Medical City, Riyadh, Kingdom of Saudi Arabia

Received 16th November 2020. Accepted 29th March 2021.

Address correspondence and reprint request to: Dr. Munazzah Rafique, Women's Specialized Hospital, King Fahad Medical City, Riyadh, Kingdom of Saudi Arabia.E-mail: munazzahr@yahoo.com ORCID ID: http://orcid.org/0000-0002-1751-6287

E xcess body weight is related to adverse effects on ${ }_{\text {survival, disability free life years, quality of life, and }}$ productivity. ${ }^{1}$ The higher the percentage of population that is overweight and obese, the higher the demand for health care, and the higher medical costs for obesityrelated diseases. ${ }^{2,3}$ A statistical analysis of the direct healthcare effects of obesity found that it accounts for 
$2.8 \%$ of healthcare spending accounted and infertility related increase in cost burden. ${ }^{2-4}$ Recent US data, reported that obese patients pay $46 \%$ higher hospital costs, $27 \%$ higher doctor visits and the outpatient costs, and $80 \%$ amplified spending on prescription of the drugs compared to people with normal body weight. ${ }^{5}$ Globally, the prevalence of obesity is increasing from $5 \%$ in the developing nations to $30 \%$ in the developed nations. ${ }^{6}$ In the Kingdom of Saudi Arabia, prevalence of obesity is $35.5 \% .{ }^{7}$ Given its global influence, it is a need to have a common universal norm. Although there are recommendations that one's waist-hip ratio corresponds better than the body mass index (BMI), with fitness and fertility, the latter is more commonly used. The World Health Organization (WHO) concept were followed in this study; people with $\mathrm{BMI} \geq 25 \mathrm{~kg} / \mathrm{m}^{2}$ are overweight; those with BMI $\geq 30 \mathrm{~kg} / \mathrm{m}^{2}$ are obese. ${ }^{8}$

Infertility which is defined as inability to get pregnant after more than 12 months of unprotected sexual activity, affects 1 in 7 couples worldwide. ${ }^{9}$ Obesity leads to disturbances in the hypothalamic pituitary ovarian axis leading to anovulation and infertility. ${ }^{10}$ Unexplained infertility and ovulatory defects account for $>50 \%$ of infertile causes; a large percentage of which are directly or indirectly related to obesity. ${ }^{11}$ Specifically, obesity is associated with anovulation, infertility, miscarriage, poor pregnancy and neonatal outcomes. ${ }^{9-11}$ Thus, short and long-term management of such patients is challenging because of the synergistic adverse effects of infertility and obesity. ${ }^{12}$

In-vitro fertilization/intracytoplasmic sperm injection (IVF/ICSI) is a well-established therapeutic choice, representing major economic and health effects for individuals, society and healthcare providers that can be primary costs and indirect costs. ${ }^{13}$ Direct expenses include medical sessions, medications for ovulation stimulation, testing, embryology services, ultrasound screening, treatments such as oocyte pick up, embryo transfer, hospital bills, and administrative and overhead bills for nursing and therapy services. Therefore, relative to multiple groups of obesity and its effect on pregnancy and live birth rates, we decided to quantify the cost of the IVF/ICSI cycle. The main objective of the analysis is to compare between various BMI groups the cost of IVF/ICSI, and reproductive outcomes.

Disclosure. Authors have no conflict of interests, and the work was not supported or funded by any drug company.
Methods. After the conceptualization of idea, the literature search was carried out by using $\mathrm{MeSH}$ terms involving the search engines that include Pubmed, Medline, google scholar and open literature. Related research work was then analyzed to find out extent of research carried out on this topic. Relevant papers were screened and added for discussion. A retrospective chart review was conducted between January 2017 and December 2018 at the infertility center of King Fahad Medical City (KFMC) after taking institutional review board approval and according to principles of Helsinki Declaration. The inclusion criteria were all infertile women below the age of 42 who underwent first stimulated IVF cycle. We excluded the male infertility cases, patients with comorbid conditions, those who had freeze-all embryos and cancelled cycles, and those with incomplete data. Within 3 months of the start of the new IVF cycle, BMI was registered and patients were divided into 4 BMI categories; group 1-underweight $\left(<18.5 \mathrm{~kg} / \mathrm{m}^{2}\right)$, group 2-average weight $\left(18.5-24.9 \mathrm{~kg} / \mathrm{m}^{2}\right)$, group 3-overweight $\left(25-29.9 \mathrm{~kg} / \mathrm{m}^{2}\right)$, and group 4-obese $>30 \mathrm{~kg} / \mathrm{m}^{2}$ ).

Data extracted include BMI, age of the female patients, infertility duration, infertility cause, total dosage and duration of gonadotropins utilized for the ovarian stimulation, and direct cost for blood tests and ultrasound scans for monitoring. The findings considered in the study were: day 15 human chronic gonadotr opin ( $(-\mathrm{hCG}$ ) serum pregnancy hormone test once embryo is transferred, confirming the clinical pregnancy by transvaginal ultrasound 2-4 weeks later to check for fetal heartbeat, transvaginal ultrasound for miscarriage by confirming absent fetal heart. Continuing pregnancy is described as any positive fetal heart pregnancy, visualized on ultrasound at $>11$ weeks. All women had their details linked electronically with the obstetric outcomes; in case the information was not found, patients were contacted by phone.

The initial stimulatory dose of gonadotropins was started depending on day 2 level of follicle-stimulating hormone (FSH), patient's age, BMI, and antral follicle count (150 IU of gonadotropins was given in women younger than 37 years of age, $225 \mathrm{IU}$ in women aged 37-39, in addition 300 IU for women aged 40 years or older). The patients were monitored using ultrasound reports and serum estradiol levels. A human chorionic gonadotrophin (HCG) trigger was given if minimum of 3 follicles that size greater than $17-18 \mathrm{~mm}$ in diameter were visualized by ultrasound. In all females, 2 embryos have been transferred in.

All categorical variables such as BMI, parity, miscarriage presented as numbers and percentages. 
Continuous variable age, duration of infertility and total cost are expressed as Median (interqurtile range). We used non-parametric tests when data was skewed/ non-normal data and normality of the data checked by Kolmogorov Smirnov test. Kruskal-Wallis test applied to find out median differences between BMI classifications and clinical characteristics of patients. The exact test of Chi-square/Fisher was applied on the basis of whether the predicted cell frequency was lower than 5 and the significant relation between categorical variables was determined. Data was analyzed on direct costs of IVF in each cohort. For interventions like IVF and ICSI, the costs and clinical outcomes associated with each strategy were compared for different weight groups. The average cost for each cohort of clinical testing was calculated. Regression and correlation analysis was applied to find out significant correlation between total cost (SAR) of IVF and patient's BMI. A 2-tailed $p$-value less than 0.05 considered significant for all comparisons. All data was entered and evaluated via the IBM SPSS Statistics for Windows, version XX (IBM Corp., Armonk, N.Y., USA).

Cost calculations. A bottom-up methodology was used to measure the resource utilization parameters in the reproductive endocrine and infertility medicine department (REIMD); oocyte regeneration, ultrasound scans, blood testing, drug used, embryo transfer and IVF/ICSI. As outlined in REIMD budget, all capital inputs (for example, personnel, facilities, space, and consumables) needed for individual procedures were defined and calculated by consulting with appropriate clinicians and priced using market prices for 2017-2018. The cost of r-FSH (Gonal F) was calculated at a price of 49 Saudi Riyal (SAR) (13\$) per 75 units, the cost of human menopausal gonadotropin (Merional) was calculated at a cost 40 SAR (11\$) per 75 units, and the baseline cost for IVF/ICSI procedure was calculated at 9000 SAR $(2400 \$)$ based on market price cost. The cost of biochemical pregnancy; when the pregnancy fails before ultrasound detection of it after a positive pregnancy test; was estimated on the assumption that, on average, each would require one B-HCG test and ultrasound.

Results. A total of 1157 women underwent IVF/ICSI between January 2017 and December 2018. However, 331 patients were excluded due to; freeze-all embryos $(n=209)$, cancelled cycles $(n=106)$, or cycles that were converted to intrauterine insemination $(n=16)$. A total of 826 patients who fulfilled inclusion criteria were available for analysis; group $1 \quad(n=12)$ patients $(1.5 \%)$, group $2(\mathrm{n}=176)$ patients $(21.3 \%)$, group $3(n=338)$ patients $(40.9 \%)$ and group $4(n=300)$ patients (40.9\%) (Table 1$)$.

Table 2 displays the characteristics of women in each BMI group. There was a trend towards older age in obese women. The median age was 27.5 years in women

Table 1 - Descriptive analysis of variables $(\mathrm{N}=826)$.

\begin{tabular}{|c|c|}
\hline Parameters & n (\%) \\
\hline $\begin{array}{l}\text { BMI classifications } \\
<18.5 \text { (underweight) } \\
18.5-24.9 \text { (normal) } \\
25-29.9 \text { (overweight) } \\
\geq 30 \text { (obese) }\end{array}$ & $\begin{array}{c}12(1.5) \\
176(21.3) \\
338(40.9) \\
300(36.3)\end{array}$ \\
\hline $\begin{array}{l}\text { Parity } \\
0 \\
1 \\
2\end{array}$ & $\begin{array}{c}786(95.2) \\
35(4.2) \\
5(0.6)\end{array}$ \\
\hline \multicolumn{2}{|l|}{ Causes of infertility } \\
\hline $\begin{array}{l}\text { Anovulatory infertility } \\
\text { Ovulatory } \\
\text { Anovulatory }\end{array}$ & $\begin{array}{l}680(82.3) \\
146(17.7)\end{array}$ \\
\hline $\begin{array}{l}\text { Polycystic ovarian syndrome } \\
\text { Yes } \\
\text { No }\end{array}$ & $\begin{array}{l}129(15.6) \\
697(84.4)\end{array}$ \\
\hline $\begin{array}{l}\text { Tubal factor infertility } \\
\text { Yes } \\
\text { No }\end{array}$ & $\begin{array}{c}37(4.5) \\
789(95.5)\end{array}$ \\
\hline $\begin{array}{l}\text { Unexplained infertility } \\
\text { Yes } \\
\text { No }\end{array}$ & $\begin{array}{l}123(14.9) \\
703(85.1)\end{array}$ \\
\hline $\begin{array}{l}\text { Endometriosis } \\
\text { Yes } \\
\text { No }\end{array}$ & $\begin{array}{c}35(4.2) \\
791(95.8)\end{array}$ \\
\hline $\begin{array}{l}\text { Number of embryos transferred } \\
\text { Yes } \\
\text { No }\end{array}$ & $\begin{array}{c}807(97.7) \\
19(2.3)\end{array}$ \\
\hline $\begin{array}{l}\text { Number of frozen embryos } \\
\text { Yes } \\
\text { No }\end{array}$ & $\begin{array}{l}203(24.6) \\
623(75.4)\end{array}$ \\
\hline $\begin{array}{l}\text { Treatment protocol } \\
\text { Antagonist } \\
\text { Long }\end{array}$ & $\begin{array}{l}576(69.7) \\
250(30.3)\end{array}$ \\
\hline $\begin{array}{l}\text { Assisted reproduction technique } \\
\text { IVF-ICSI } \\
\text { IVF }\end{array}$ & $\begin{array}{r}811(98.2) \\
15(1.8)\end{array}$ \\
\hline $\begin{array}{l}\text { Gonadotropins } \\
\text { HMG (merional) } \\
\text { r-FSH (gonal-F) }\end{array}$ & $\begin{array}{l}413(50.0) \\
413(50.0)\end{array}$ \\
\hline $\begin{array}{l}\text { Clinical pregnancy rate } \\
\text { Yes } \\
\text { No }\end{array}$ & $\begin{array}{l}347(42.0) \\
479(58.0)\end{array}$ \\
\hline $\begin{array}{l}\text { Miscarriage rate } \\
\text { Yes } \\
\text { No }\end{array}$ & $\begin{array}{l}110(13.3) \\
716(86.7)\end{array}$ \\
\hline $\begin{array}{l}\text { Live birth rate } \\
\text { Yes } \\
\text { No }\end{array}$ & $\begin{array}{l}120(14.5) \\
706(85.5)\end{array}$ \\
\hline $\begin{array}{l}\text { HMG: human } \\
\text { r-FSH: recombina }\end{array}$ & $\begin{array}{l}\text { ins, } \\
\text { rmone }\end{array}$ \\
\hline
\end{tabular}


IVF/ICSI cost in infertility ... Rafique et al

Table 2 - Impact and association of body mass index (BMI) with respect to clinical characteristics of the study.

\begin{tabular}{|c|c|c|c|c|c|c|}
\hline Parameters & Description & $\begin{array}{c}<18.5 \\
\text { (Underweight) }\end{array}$ & $\begin{array}{l}18.5-24.9 \\
\text { (Normal) }\end{array}$ & $\begin{array}{c}25-29.9 \\
\text { (Overweight) }\end{array}$ & $\begin{array}{c}\geq 30 \\
\text { (Obese) }\end{array}$ & $P$-value \\
\hline Age & Median (IQR) & $27.5(31.75-25.5)$ & $31(35-28)$ & $33(37-29)$ & $33(38-29.25)$ & $<0.001^{*}$ \\
\hline BMI & Median (IQR) & $17.2(18-16.25)$ & $22.8(23.88-21.2)$ & $27.4(28.7-26.3)$ & $32.2(33.9-31)$ & $<0.001^{*}$ \\
\hline Duration of infertility & Median (IQR) & $5.5(8.75-4)$ & $5(8-4)$ & $6(8-4)$ & $7(10-5)$ & $0.022^{*}$ \\
\hline FSH (IU/L) & Median (IQR) & $7.2(8.76-5.21)$ & $6.5(7.6-4.7)$ & $5.9(6.92-4.33)$ & $6.3(7.4-4.71)$ & 0.112 \\
\hline LH (IU/L) & Median (IQR) & $7.65(8.43-5.59)$ & $5.6(8.3-3.75)$ & $5.1(7.98-3.75)$ & $6.2(8.95-4.15)$ & $0.030^{*}$ \\
\hline $\mathrm{E} 2(\mathrm{pmol} / \mathrm{L})$ & Median (IQR) & $119(259.5-87.25)$ & $146.5(250.5-86.78)$ & $145.5(213-56.69)$ & $143(220-49)$ & 0.891 \\
\hline Prolactin (mIU/L) & Median (IQR) & $203(306-19.8)$ & $234(409.75-16.2)$ & $204(378-14.25)$ & $208(370-16)$ & 0.945 \\
\hline TSH (mIU/L) & Median (IQR) & $1.2(4.65-0.84)$ & $2.6(4.7-1.89)$ & $2.52(4.78-1.6)$ & $2.54(4.13-1.49)$ & 0.329 \\
\hline $\begin{array}{l}\text { Number of eggs } \\
\text { fertilized }\end{array}$ & Median (IQR) & $3.5(6.5-1.0)$ & $2(4-1.75)$ & $3(4-2)$ & $3(4-2)$ & 0.113 \\
\hline $\begin{array}{l}\text { Number of aspirated } \\
\text { follicles }\end{array}$ & Median (IQR) & $8.5(15-5.25)$ & $6(10.75-4)$ & $7(11-4)$ & $7(11-4)$ & 0.873 \\
\hline $\begin{array}{l}\text { Dose of r-FSH } \\
\text { (Gonal-F) (IU) }\end{array}$ & Median (IQR) & $150(150-112)$ & $150(206-112)$ & $150(225-150)$ & $150(225-150)$ & 0.486 \\
\hline $\begin{array}{l}\text { Dose of HMG } \\
\text { (Merional)(IU) }\end{array}$ & Median (IQR) & $150(375-150)$ & $225(300-150)$ & $225(300-150)$ & $225(300-150)$ & 0.685 \\
\hline Treatment days & Median (IQR) & $10(11-9)$ & $10(11-9)$ & $11(13-9)$ & $11(13-9)$ & 0.562 \\
\hline \multirow{2}{*}{$\begin{array}{l}\text { Patients with embryo } \\
\text { transfer (\%) }\end{array}$} & Yes & $11(91.7)$ & $173(98.3)$ & $333(98.5)$ & $290(96.7)$ & \multirow{2}{*}{0.198} \\
\hline & No & $1(8.3)$ & $3(1.7)$ & $5(1.5)$ & $10(3.3)$ & \\
\hline \multirow{2}{*}{$\begin{array}{l}\text { Patients with frozen } \\
\text { embryos (\%) }\end{array}$} & Yes & $4(33.3)$ & $36(20.5)$ & $86(25.4)$ & $77(25.7)$ & \multirow{2}{*}{0.486} \\
\hline & No & $8(66.7)$ & $140(79.5)$ & $252(74.6)$ & $223(74.3)$ & \\
\hline \multirow[t]{2}{*}{ Miscarriages (\%) } & Yes & $0(0.0)$ & $18(10.2)$ & $45(13.3)$ & $47(15.7)$ & \multirow[b]{2}{*}{0.192} \\
\hline & No & $12(100.0)$ & $158(89.8)$ & $293(86.7)$ & $253(84.3)$ & \\
\hline \multirow{2}{*}{$\begin{array}{l}\text { Assisted reproduction } \\
\text { technique }\end{array}$} & IVF-ICSI & $12(100.0)$ & $173(98.3)$ & $332(98.2)$ & $294(98.0)$ & \multirow{2}{*}{0.961} \\
\hline & IVF & $0(0.0)$ & $3(1.7)$ & $6(1.8)$ & $6(2.0)$ & \\
\hline \multirow[t]{2}{*}{ Gonadotropins } & HMG (Merional) & $5(41.7)$ & $95(54.0)$ & $161(47.6)$ & $152(50.7)$ & \multirow{2}{*}{0.521} \\
\hline & r-FSH (Gonal-F) & $7(58.3)$ & $81(46.0)$ & $177(52.4)$ & $148(49.3)$ & \\
\hline \multirow[t]{2}{*}{ Clinical pregnancy } & Yes & $6(50.0)$ & $63(35.8)$ & $144(42.6)$ & $134(44.7)$ & \multirow{2}{*}{0.259} \\
\hline & No & $6(50.0)$ & $113(64.2)$ & $194(57.4)$ & $166(55.3)$ & \\
\hline \multirow[t]{2}{*}{ Live birth rate } & Yes & $1(8.3)$ & $23(13.1)$ & $48(14.2)$ & $48(16.0)$ & \multirow{2}{*}{0.747} \\
\hline & No & $11(91.7)$ & $153(86.9)$ & $290(85.8)$ & $252(84.0)$ & \\
\hline
\end{tabular}

FSH: follicle-stimulating hormone, LH: luteinizing hormone, TSH: thyroid stimulating hormone, HMG: human menopausal gonadotropins, IQR: interquartile range IVF-ICSI: in-vitro fertilization/intracytoplasmic sperm injection, r-FSH: recombinant follicle stimulating hormone 
Table 3 - Comparative analysis of IVF cost and patient's body mass index.

\begin{tabular}{|c|c|c|c|c|c|c|}
\hline Parameters & Description & $\begin{array}{c}<18.5 \\
\text { (Underweight) }\end{array}$ & $\begin{array}{c}18.5-24.9 \\
(\text { Normal) }\end{array}$ & $\begin{array}{c}25-29.9 \\
\text { (Overweight) }\end{array}$ & $\begin{array}{c}\geq 30 \\
\text { (Obese) }\end{array}$ & $P$-value \\
\hline $\begin{array}{l}\text { Total cost } \\
\text { HMG } \\
\text { (Merional) }\end{array}$ & Median (IQR) & $10280(11680-9760)$ & $10560(11160-10120)$ & $10440(10920-10040)$ & $10560(10920-10140)$ & 0.712 \\
\hline $\begin{array}{l}\text { Total cost } \\
\text { r-FSH } \\
\text { (Gonal-F) }\end{array}$ & Median (IQR) & $10200(10320-10080)$ & $10200(10590-10080)$ & $10440(10800-10080)$ & $10320(10605-10080)$ & 0.254 \\
\hline $\begin{array}{l}\text { Total cost of } \\
\text { injections }\end{array}$ & Median (IQR) & $1240(1410-1080)$ & $1380(2055-1080)$ & $1440(1920-1080)$ & $1440(1800-1080)$ & 0.598 \\
\hline $\begin{array}{l}\text { Total cost of } \\
\text { IVF/IVF-ICSI } \\
\text { (SR) }\end{array}$ & Median (IQR) & $10240(10410-10080)$ & $10380(11055-10080)$ & $10440(10920-10080)$ & $10440(10800-10080)$ & 0.598 \\
\hline
\end{tabular}

HMG: human menopausal gonadotropins, r-FSH: recombinant follicle stimulating hormone, IQR: interquartile range,

IVF-ICSI: in-vitro fertilization/intracytoplasmic sperm injection

who were underweight, 31 years in women with normal weight, 33 years in overweight women, and 33 years in obese women $(p<0.001)$. The duration of infertility was similar across the groups except in the obese group where the duration of infertility was longer, a range of 5 to 10 years and a median of 7 years in the obese group.

There were no statistical significant differences in baseline serum FSH, TSH, prolactin and estradiol among the groups; however, there was statistical difference in the level of LH. The median was 7.65 IU/L in women who were underweight, $5.6 \mathrm{IU} / \mathrm{L}$ in women with normal weight, 5.1I U/L in women who were overweight, and $6.2 \mathrm{IU} / \mathrm{L}$ in those women who were obese $(p=0.03)$, (Table 2$)$. There were no statistical significant differences for number of days required for stimulation among groups; 10 days for women with underweight and normal weight and 11 days for women with overweight and obese group respectively $(p=0.6)$. Majority of the patients had IVF-ICSI cycles $(\mathrm{n}=811,98.2 \%)$ in comparison to IVF $(\mathrm{n}=15,1.8 \%)$ (Table 2), and 576 patients (69.7\%) had antagonist ovarian stimulation protocol, and $250(30.3 \%)$ had day 21 long ovarian stimulation protocol (Table 2). Of the 826 patients, $347(42 \%)$ had a positive pregnancy test and 479 women $(58 \%)$ had a negative pregnancy test. There was no statistical significant difference in the pregnancy rate among the different BMI groups, pregnancy occurred in 6 women in group $1(50 \%)$, in 63 women in group $2(35.8 \%), 144$ (42.6\%) women occurred in group 3, and 134 (44.7\%) women occurred in group 4 (Table 2).
No statistical significant differences were seen in miscarriage rates between groups: 18 (10.2\%), normal BMI; 45 (13.3\%), overweight $47(15.7 \%)$ and among obese women $(p=0.2)$.

No statistical significant differences were seen with regard to frozen embryos among group; 86 (25.4\%) in the overweight and $77(25.7 \%)$ in the obese group verses $36(20.5 \%)$ in the normal weight group.

There was no statistical significant difference for the LBR among the BMI groups, with the occurrence of LBR in 23 women with normal BMI (13.1\%), in 48 $(14.2 \%)$ women who were overweight, in $48(16 \%)$ in women who were obese ( $p=0.7)$ (Table 2). Besides, the median cost of medications in different groups showed trend increase; however, it was not statistically significant. The cost was 1240 SAR for group 1,1380 SAR for group 2, 1440 for group 3 and $4(p=0.59)$ (Table 3$)$. The median total cost for IVF/ICSI treatment cycle did not differ across BMI groups; the cost was 10,240 SAR for underweight women, 10,380 SAR for normal weight women, 10,440 SAR for overweight women, and 10,440 SAR for obese women $(p=0.62)$ (Table 3).

Discussion. The management of infertility has been transformed by the use of assisted reproductive technologies (ART). These developments have a medical, reproductive and economic impact with the cost of a single new IVF in the United States as a proportion of an individual's annual disposable income was $50 \%$; in the United Kingdom, Scandinavian countries, and 
Australia, about 20\%; and in Japan, 12\%. ${ }^{14}$ In women with anovulation, where clomiphene citrate is used for ovulation induction (OI) in overweight and obese cohort of women, resulted in lower ovulation and total live birth rates, but if $\mathrm{OI}$ is successful, no difference in pregnancy rates is seen in different weight categories. ${ }^{15}$ Higher cancellation rates and substantially higher miscarriage rates are also correlated with obesity, resulting in decreased live birth rates. ${ }^{16}$ The pregnancy rate and live birth rate decreases due to higher miscarriage rates among obese women such as those found in our study. ${ }^{17}$ Lifestyle changes and weight loss programs for obese women have restored menstrual regularity, ovulation and improved the likelihood of conception. ${ }^{18} \mathrm{~A}$ better awareness of the link between the cost, use, and healthy clinical practice of IVF therapy would not only promote equal access to care for patients with subfertility, but also enable children born from IVF get the best possible start in life. ${ }^{19}$ Previous studies showed relationship between obesity and ovulatory dysfunction and thus need a higher dose of gonadotrophins; similarly, in our results there was slight increase in gonadotropin requirement in the overweight and obese group, but this did not achieve statistical significance. This is because protocols modify dosage based on the BMI for the IVF cycle. ${ }^{20}$ Conflicting results about pregnancy and its outcomes have been found in previous studies, ${ }^{15-19}$ but we found that the higher the BMI, the higher the likelihood of having a miscarriage.

The outcomes per IVF/ICSI may vary because of factors that can affect fertility like age, sperm quality, and comorbid conditions in both partners. In the literature, variable results were obtained for the outcomes in IVF/ ICSI for overweight and obese women. ${ }^{17,18} \mathrm{We}$ found no statistically significant differences in IVF/ICSI outcomes among women with different BMI categories. In addition, obesity was associated with pregnancy complications such as high risk of miscarriage, congenital defects, gestational diabetes, hypertensive diseases. It also leads to prolonged labor, fetal macrosomia and increased need for operative delivery, shoulder dystocia, and postpartum hemorrhage. ${ }^{19}$ A system within which the effects of fertility therapy and the implications of the subsequent pregnancy can be measured concurrently for infertile women in various groups of body weight needs to be established. It will help reduce the indirect treatment cost for infertility patients by producing a provisional model of working on lifestyle modifications to increase the chances of natural conception. The estimated costs of IVF/ICSI will help us identify costeffective measures to avoid unnecessary interventions.
Study limitations. This study was conducted at a single center therefore, a large sample with multicenter study, can find statistical significance even when the differences or associations are small/weak. Additionally, doctors, researcher and clinicians sometimes misinterpret statistically significant result as being practically or clinically important. But cost significance is not the same as practical significance or importance. Additionally, women in this study were randomly selected on fulfilling the eligibility criteria after initial screening and many women with BMI greater than $35 \mathrm{~kg} / \mathrm{m}^{2}$ were not eligible for treatment, and thus might alter the true number of the obese women in this study. Consequently, our results are not generalizable for women with obesity of BMI more than $35 \mathrm{~kg} / \mathrm{m}^{2}$.

In conclusion, our results suggest that being overweight or obese does not significantly increase the costs of IVF-ICSI. Women could get pregnant if they are overweight or obese but pregnancy might be high risk. Therefore, weight loss measures should be introduced before starting IVF treatment to improve pregnancy outcomes, and reduce obesity linked pregnancy complications.

Acknowledgment. We would like to thank the Infertility Center and Research Center of King Fahad Medical City, Riyadh, Saudi Arabia for providing the data and grant for this research. We acknowledge Enago English editing services for editing the manuscript.

\section{References}

1. Kjellberg J, Tange Larsen A, Ibsen R, Højgaard B. The socioeconomic burden of obesity. Obes Facts 2017; 10: 493-502.

2. Yusefzadeh H, Rashidi A, Rahimi B. Economic burden of obesity: A systematic review. Social Health and Behavior 2019; 2: 7 .

3. Jahromi AS, Rahmanian K. Relation of health-related quality of life with abnormal weight: A cross-sectional study prior to the weight reduction intervention. J Family Med Prim Care 2020; 9: 4662-4666.

4. Anekwe CV, Jarrell AR, Townsend MJ, Gaudier GI, Hiserodt JM, Stanford FC. Socioeconomics of Obesity. Curr Obes Rep 2020; 9: 272-279.

5. Bozzi DG, Nicholas LH. A causal estimate of long-term health care spending attributable to body mass index among adults. Econ Hum Biol 2021; 41: 100985.

6. Masood M, Reidpath DD. Intraclass correlation and design effect in BMI, physical activity and diet: a cross-sectional study of 56 countries. BMJ Open 2016; 6: e008173.

7. Rafique M, Nuzhat A. Role of obesity in female infertility and assisted reproductive technology (ART) outcomes. Saudi J Obes 2016; 4: 75-79.

8. Fichman V, Costa RS, Miglioli TC, Marinheiro LP. Association of obesity and anovulatory infertility. Einstein (Sao Paulo) 2020; 18: eAO5150. 
9. Vander Borght M, Wyns C. Fertility and infertility: definition and epidemiology. Clin Biochem 2018; 62: 2-10.

10. Silvestris E, de Pergola G, Rosania R, Loverro G. Obesity as disruptor of the female fertility. Reprod Biol Endocrinol 2018; 16: 22.

11. Nazem TG, Aharon D, Copperman AB. Evaluation of the infertile couple. Obstet Gynecol 2020: 263-273.

12. Narice BF, Metwally M. Evidence-based assisted reproduction in obese women. Obesity and Gynecology 2020: 1. 127-133.

13. Pan W, Tu H, Jin L, Hu C, Li Y, Wang R, et al. Decision analysis about the cost-effectiveness of different in vitro fertilizationembryo transfer protocol under considering governments, hospitals, and patient. Medicine (Baltimore) 2019; 98: e15492.

14. De Geyter C. Assisted reproductive technology: impact on society and need for surveillance. Best Pract Res Clin Endocrinol Metab 2019; 33: 3-8.

15. Ellakwa HE, Sanad ZF, Hamza HA, Emara MA, Elsayed MA. Predictors of patient responses to ovulation induction with clomiphene citrate in patients with polycystic ovary syndrome experiencing infertility. Int J Gynaecol Obstet 2016; 133: 59-63.
16. Grieger JA, Bianco-Miotto T, Grzeskowiak LE, Leemaqz SY, Poston L, McCowan LM, et al. Metabolic syndrome in pregnancy and risk for adverse pregnancy outcomes: A prospective cohort of nulliparous women. PLoS Med 2018; 15: e1002710.

17. Sampo AV, Palena C, Ganzer L, Maccari V, Estofán G, Hernández M. The adverse effect of overweight in assisted reproduction treatment outcomes. JBRA Assist Reprod 2017; 21: $212-216$.

18. Silvestris E, de Pergola G, Rosania R, Loverro G. Obesity as disruptor of the female fertility. Reprod Biol Endocrinol 2018; 16: 22 .

19. van Eekelen R, Eijkemans MJ, Mochtar M, Mol F, Mol BW, Groen H, et al. Cost-effectiveness of medically assisted reproduction or expectant management for unexplained subfertility: when to start treatment? Hum Reprod 2020; 35 : 2037-2046. 